\title{
Mapping of QTL for Fusarium head blight resistance and morphological and developmental traits in three backcross populations derived from Triticum dicoccum $\times$ Triticum durum
}

\author{
Maria Buerstmayr • Karin Huber • \\ Johannes Heckmann • Barbara Steiner • \\ James C. Nelson · Hermann Buerstmayr
}

Received: 25 May 2012 / Accepted: 15 July 2012/Published online: 25 August 2012

(C) The Author(s) 2012. This article is published with open access at Springerlink.com

\begin{abstract}
Breeding for resistance to Fusarium head blight (FHB) in durum wheat continues to be hindered by the lack of effective resistance sources. Only limited information is available on resistance QTL for FHB in tetraploid wheat. In this study, resistance to FHB of a Triticum dicoccum line in the background of three Austrian T. durum cultivars was genetically characterized. Three populations of $\mathrm{BC}_{1} \mathrm{~F}_{4}$ derived RILs were developed from crosses between the resistant donor line T. dicoccum-161 and the Austrian T. durum recipient varieties DS-131621, Floradur and Helidur. About $130 \quad \mathrm{BC}_{1} \mathrm{~F}_{4}$-derived lines per population were evaluated for FHB response using artificial spray
\end{abstract}

Communicated by M. Sorrells.

Electronic supplementary material The online version of this article (doi:10.1007/s00122-012-1951-2) contains supplementary material, which is available to authorized users.

M. Buerstmayr $\cdot$ K. Huber $\cdot$ J. Heckmann - B. Steiner ·

H. Buerstmayr $(\square)$

Department for Agrobiotechnology Tulln, BOKU-University

of Natural Resources and Life Sciences-Vienna,

Konrad Lorenz Str. 20, 3430 Tulln, Austria

e-mail: hermann.buerstmayr@boku.ac.at

Present Address:

K. Huber

Presse und Informationsdienst Agrarisches Informationszentrum (AIZ), Schauflergasse 6, 1014 Vienna, Austria

Present Address:

J. Heckmann

Rijk Zwaan Nederland B.V., Burgemeester Crezéelaan,

P.O. Box 40, 2678 ZG De Lier, The Netherlands

J. C. Nelson

Department of Plant Pathology, Kansas State University,

Manhattan, KS 66506, USA inoculation in four field experiments during two seasons. Lines were genetically fingerprinted using SSR and AFLP markers. Genomic regions on chromosomes 3B, 4B, 6A, $6 \mathrm{~B}$ and $7 \mathrm{~B}$ were significantly associated with FHB severity. FHB resistance QTL on $6 \mathrm{~B}$ and $7 \mathrm{~B}$ were identified in two populations and a resistance QTL on 4B appeared in three populations. The alleles that enhanced FHB resistance were derived from the $T$. dicoccum parent, except for the QTL on chromosome 3B. All QTL except the QTL on 6A mapped to genomic regions where QTL for FHB have previously been reported in hexaploid wheat. QTL on 3B and 6B coincided with $F h b 1$ and $F h b 2$, respectively. This implies that tetraploid and hexaploid wheat share common genomic regions associated with FHB resistance. QTL for FHB resistance on $4 \mathrm{~B}$ co-located with a major QTL for plant height and mapped at the position of the Rht-Bl gene, while QTL on 7B overlapped with QTL for flowering time.

\section{Introduction}

Fusarium head blight (FHB), caused by several members of the Fusarium genus, occurs frequently in small grain cereals in temperate regions throughout the world (McMullen et al. 1997). FHB leads to severe losses not only in grain yield but also in quality; contamination with toxic fungal metabolites such as deoxynivalenol or nivalenol render harvested grain unsuitable for consumption as food and feed (Gilbert and Tekauz 2000). This contamination is especially critical for durum wheat, which is used primarily for human consumption. The best economic and ecological strategy for reducing FHB damage is the utilization of resistant cultivars.

Although a range of Fusarium species cause FHB and different Fusarium strains may differ widely in 
aggressiveness, no biological races with a specific hostpathogen interaction have been reported (Van Eeuwijk et al. 1995). Resistance to FHB is complex and quantitatively inherited; infection and development of FHB depend largely on environment, and genotype $\times$ environment interaction complicates resistance evaluation (Miedaner et al. 2001). Flowering time is the most sensitive plant development stage for FHB infection (Atanasoff 1920; Parry et al. 1995); warm temperature (Andersen 1948; Parry et al. 1995) and high humidity during flowering promote infection (Cook 1981). Both active resistance factors, which include physiological processes (Crute et al. 1985), and passive factors, such as plant height, spike architecture and flowering date, influence infection and/or disease development (Buerstmayr et al. 2009; Mesterhazy 1995) and it may be difficult to dissect resistance factors. Thus, considering these plant traits in the analysis of FHB resistance is important. The distinction between resistance to initial infection (type 1) and resistance to fungal spread of the pathogen within the spike (type 2) first described by Schroeder and Christensen (1963) is widely accepted. These resistance types can be distinguished by quantitative trait loci/locus (QTL) studies employing suitable inoculation and assessment methods (Buerstmayr et al. 2009).

In bread wheat numerous QTL have been described, for example the major Fhbl QTL on chromosome 3BS and $F h b 2$ on chromosome 6BS have repeatedly been found in independent QTL studies (Buerstmayr et al. 2009). QTL corresponding to the Fhb2 locus were detected in tetraploid wheat as well (Somers et al. 2006). But of 52 QTL studies reviewed by Buerstmayr et al. (2009), only four concern resistance sources of tetraploid wheat. Although an extensive collection of about 6,000 durum wheat accessions were screened for FHB resistance, none showed enhanced resistance, and a further screening survey of material from CIMMYT and ICARDA identified only five lines-from a Tunisian source-that exhibited moderate resistance to FHB spread (Elias et al. 2005; Huhn et al. 2012). It was accordingly speculated that durum wheat either lacks resistance genes or carries effective susceptibility factors and/or suppressor genes that compromise FHB resistance (Ban and Watanabe 2001; Kishii et al. 2005). Indeed, a QTL that increased FHB susceptibility was reported at chromosome $2 \mathrm{~A}$ of the $T$. dicoccoides line Israel A (Garvin et al. 2009). Fakhfakh et al. (2011) hypothesized that the $\mathrm{D}$ genome of hexaploid wheat encodes resistance-inducing factors that are missing in tetraploid wheat. Gilbert et al. (2000) studied the influence of the $\mathrm{D}$ genome on $\mathrm{F}_{1}$ and $\mathrm{F}_{2}$ pentaploid plants of crosses from resistant lines of Sumai-3, Ning8331 and 93FHB21 to the susceptible tetraploids Stewart 63 and DT486, but they did not find a relationship between the presence/absence of D chromosomes and FHB reaction.
Durum wheat accounts for only $4 \%$ of total wheat production worldwide (Gill et al. 2004) so that activity in durum wheat improvement is lower than in bread wheat. The tetraploidy of durum wheat and limited breeding efforts in this relatively recent crop may have led to a narrow genetic base compared to hexaploid wheat (Oliver et al. 2008). Attempts to transfer resistance from hexaploid into tetraploid wheat have met with limited success (Gilbert et al. 2000; Oliver et al. 2007; authors' unpublished results). For this reason, studies have been conducted to find resistance sources in cultivated or wild relatives of durum wheat (Buerstmayr et al. 2003; Clarke et al. 2004; Kishii et al. 2005; Miller et al. 1998; Oliver et al. 2004, 2007, 2008). Several moderately FHB-resistant accessions of wild emmer wheat, $T$. dicoccoides (Buerstmayr et al. 2003; Miller et al. 1998; Oliver et al. 2007), cultivated emmer wheat, T. dicoccum, and Persian wheat, T. carthlicum (Oliver et al. 2008), have been identified. Three sets of disomic chromosome substitution lines derived from T. dicoccoides accessions (Israel A, PI478742 and PI481521) in the genetic background of the T. durum cultivar Langdon (LDN) (Joppa and Williams 1988; Kumar et al. 2007) were tested for FHB response (Stack et al. 2002). Subsequent studies mapped QTL for FHB resistance derived from $T$. dicoccoides accession Israel A on chromosome 3A near Xgwm2 (Chen et al. 2007; Otto et al. 2002), and on the short arm of chromosome 6B (Stack and Faris 2006). The resistance of $T$. dicoccoides accession PI478742 on chromosome 7A could be assigned to 7AL (Kumar et al. 2007). In a $\mathrm{BC}_{1}$-derived RIL population from the cross of $T$. dicoccoides accession Mt. Hermon \#22 with the T. durum cultivar Helidur, four QTL were discovered and mapped to chromosomes 3A, 4A (with the resistant allele from T. dicoccoides), 2B and 4B (resistant allele from T. durum). The QTL with the largest effect was identified on $3 \mathrm{~A}$ near Xgwm2 (Gladysz et al. 2007) and colocalizes with the QTL derived from the resistance source of Israel A. In a doubledhaploid population from a cross of the T. durum cultivar Strongfield with the $T$. carthlicum cultivar Blackbird, two significant QTL for FHB spread within the spike were found, mapping to chromosome arms 2BL and 6BS (Somers et al. 2006). Notably, the 6BS QTL derived from Blackbird appeared to coincide with Fhb2 and the QTL on chromosome 2BL derived from durum parent Strongfield covers the same genomic region as the QTL of the T. durum cultivar Helidur. Ghavami et al. (2011) used breeding populations derived from several crosses of moderately resistant Tunisian durum wheat accessions with North Dakota durum lines for bi-parental and association mapping. They discovered a consistent type 2 resistance QTL at chromosome arm 5BL, at which, interestingly, the resistanceimproving allele derived from the moderately susceptible T. durum cultivar Lebsock and not the Tunisian durum parent. 
The most FHB-resistant tetraploid wheat line tested so far at IFA Tulln (Austria) has been T. dicoccum line 161 (hereafter Td161). This line shows a remarkable level of FHB resistance in replicated experiments, both after single-spikelet inoculation and after spray inoculation in field and greenhouse experiments (unpublished results). The objective of the present investigation was to dissect the FHB resistance of Td161 genetically and to study the influence of plant architecture and flowering date on disease development. For this purpose we generated three $\mathrm{BC}_{1} \mathrm{~F}_{4}$ populations from crosses of Td161 with three different well adapted but FHB-susceptible Austrian T. durum cultivars. The aim of a backcross step to the respective $T$. durum parents was to provide an additional round of recombination and to increase the proportion of the overall genome of the $T$. durum parents, so that resistance from $T$. dicoccum could be tested in an agronomically acceptable genetic background. Using spray inoculation, we evaluated the overall FHB resistance conferred by Td161 simultaneously in the genetic background of these three modern durum cultivars, allowing detection, comparison and validation of the effectiveness of FHB resistance QTL.

\section{Materials and methods}

\section{Plant material}

The Fusarium-resistant homozygous $T$. dicoccum line Td161 and three susceptible T. durum wheat varieties were used to generate three populations segregating for FHB resistance. Td161 was provided by Dr. Jeannie Gilbert (Agriculture and Agri-Food Canada, Winnipeg). Td161 is a hulled wheat, has a long and dense-spike phenotype, and is tall with a tendency to lodging. The Austrian T. durum breeding line DS-131621 (abbreviated DS) with pedigree CIMMYT-4833//Cando/Valgerado and T. durum cultivars Floradur with pedigree Helidur/CIMMYT-4833 and Helidur with pedigree Pandur/CPB132/3/Valdur//Pandur/Valgerado were used as the recurrent parents. The $T$. durum parents were provided by Saatzucht-Donau, Austria. In contrast to Td161, the recurrent parents are relatively short (carrying the $R h t-B 1 b$ allele for reduced plant height) and possess a dense-spike phenotype. Typical heads of Td161, Helidur and Floradur are shown in Electronic Supplementary Material Fig. S1. $F_{1}$ plants from each cross were backcrossed as the female to their respective $T$. durum parent. $\mathrm{BC}_{1} \mathrm{~F}_{1}$ plants were advanced by single-seed descent to the $\mathrm{BC}_{1} \mathrm{~F}_{4}$ generation. The resulting $\mathrm{BC}_{1} \mathrm{~F}_{4}$ plants were bulk propagated for multi-environment testing as $\mathrm{BC}_{1} \mathrm{~F}_{4: 5}$ lines. The three $\mathrm{BC}_{1} \mathrm{~F}_{4}$ populations, here abbreviated as DTd (recurrent parent DS-131621), FTd (Floradur) and
HTd (Helidur), comprised 134, 129 and $126 \mathrm{BC}_{1} \mathrm{~F}_{4}$ lines, respectively.

Field experiments and disease assessment

All populations were tested in four field experiments at IFA-Tulln, $30 \mathrm{~km}$ west of Vienna (1604'E, 48 $19^{\circ} \mathrm{N}$, $177 \mathrm{~m}$ above sea level) in 2006 and 2008. In each year two experiments were conducted, one inoculated with $F$. culmorum $(\mathrm{Fc})$ and the other with $F$. graminearum $(\mathrm{Fg})$. Accordingly, experiments are encoded by isolate and year as Fc06, Fc08, Fg06 and Fg08. Experiments were arranged in a randomized complete block design with two blocks. Plots consisted of double rows of $1 \mathrm{~m}$ length and $17 \mathrm{~cm}$ spacing. In 2006 the sowing time was early spring. The two replications were sown 1 week apart. One replication of the 2008 experiment was sown in November 2007 and the second in early spring 2008. These staggered sowing dates led to slightly different flowering dates between the blocks. Crop management was essentially as described by Buerstmayr et al. (2002). All experiments were spray inoculated with a motor-driven backpack sprayer in the late afternoon. Each plot was individually inoculated twice, the first time when $50 \%$ of the heads within a plot were flowering and the second time 2 days later. Plots were mist irrigated for $20 \mathrm{~h}$ after inoculation to facilitate infection. For inoculation, macroconidial suspensions of either F. culmorum single-spore isolate 'IFA-106', prepared as described by Buerstmayr et al. (2000), or F. graminearum single-spore isolate 'IFA-65', prepared as described by Buerstmayr et al. (2003), were used. Aliquots of conidia stock solutions were stored at $-30{ }^{\circ} \mathrm{C}$ and diluted with deionized water to a final spore concentration of $2.5 \times 10^{4} \mathrm{~mL}^{-1}$ just prior to inoculation. FHB severity was averaged as the visually estimated percentage of infected spikelets per plot on days 10, 14, 18, 22 and 26 after first inoculation. This inoculation and scoring method mimics a natural epidemic and reflects overall resistance, but does not distinguish specific types of resistance (Buerstmayr et al. 2009). Date of anthesis was recorded for each plot and converted into number of days after May 1. Plant height was measured for experiments Fc06 and Fg08 in cm. Awn length was visually scored from 0 (short) to 9 (long) in experiments $\mathrm{Fc08}$ and $\mathrm{Fg} 08$. Spike density was scored from 0 (loose) to 9 (very compact) in experiment $\mathrm{Fg} 08$. Awn length and ear compactness were visually assessed in the field after anthesis.

Molecular genetic characterization

117 lines of population DTd and 120 lines of population FTd and 120 lines of population HTd were randomly chosen for marker analysis. Total genomic DNA was 
isolated from young leaves of 10 pooled plants of each backcross line and of the parental lines according to the protocol of Saghai Maroof et al. (1984). All populations were genotyped with simple sequence repeat (SSR) and amplified fragment length polymorphism (AFLP) markers and allele-specific SNP markers for Rht-Bla (tall) and Rht$B 1 b$ (short) (Ellis et al. 2002). A polymorphism survey on the parents was carried out with 237 SSR primer pairs, comprising 158 GWM markers (Roeder et al. 1998), 71 BARC markers (Song et al. 2005), 6 WMC markers (Somers et al. 2004), 1 GDM marker (Pestsova et al. 2000), the umn10 marker (Liu et al. 2008) and allele-specific RhtB1 markers (Ellis et al. 2002). From these primer pairs 85 were chosen for screening the DTd, FTd and HTd population, respectively. PCR and fragment detection were conducted as described by Steiner et al. (2004). AFLP marker analysis (Vos et al. 1995) was performed using MseI/Sse8387I restriction enzymes as described by Hartl et al. (1999) and Buerstmayr et al. (2002). For populations DTd, FTd, and HTd, 21, 24 and 32 selective AFLP primer combinations were used, respectively. For populations FTd and HTd, detection of AFLP fragments was carried out on a LI-COR 4200 dual-dye DNA analyzer (LI-COR Biosciences, Lincoln, Nebraska, USA), and for population DTd a Typhoon-TRIO fluorescence scanner (GE Healthcare, http://www.gehealthcare.com) was used. AFLP markers were abbreviated according to the standard list for AFLP primer nomenclature (http://wheat.pw.usda.gov/ggpages/ keygeneAFLPs.html) followed by the starting character of the $T$. durum recurrent-parent name and a number assigned to each unique polymorphic locus. Identical AFLP loci of two or all three populations were encoded by the starting character and corresponding locus number of the respective population.

The T. durum parents and Td161 together with hexaploid wheat Sumai-3, CM-82036 and W14 were genotyped with selected markers close to Fhbl (umn10, barc133, gwm533, gwm493, gwm133, barc147) and Fhb2 (wmc397, wmc398, gwm644) loci. All three hexaploid wheats carry the Fhb1 resistance allele, and Sumai-3 and W14 also carry the $F h b 2$ resistance allele.

Statistical analysis

\section{Field data}

Area under the disease progress curve (AUDPC), calculated according to Buerstmayr et al. (2000), was used as a measure of FHB severity. Pearson correlation coefficients between the recorded traits were estimated based on mean across experiments, and for FHB severity, between each experiment combination. The effects of replication within experiments, experiment, genotype, and genotype-by- experiment interaction were estimated using the general linear model (GLM) procedure, with all effects fixed. For the estimation of variance components and broad-sense heritability all effects were considered random. Broadsense heritability was estimated from variance components with the equation $H^{2}=\sigma_{\mathrm{G}}^{2} /\left(\sigma_{\mathrm{G}}^{2}+\sigma_{\mathrm{G} \times \mathrm{E}}^{2} / e+\sigma_{\mathrm{E}}^{2} / e n\right)$, where $\sigma_{\mathrm{G}}^{2}=$ genotypic variance, $\sigma_{\mathrm{GxE}}^{2}=$ genotype-by-experiment interaction variance, $\sigma_{\mathrm{E}}^{2}=$ error variance, $e=$ number of experiments and $n=$ number of replications (Nyquist 1991). ANOVA and correlation analysis were calculated in SAS/STAT version 9.2 (SAS Institute Inc 2008).

\section{Linkage mapping}

Segregation deviation of individual markers from expected ratios was determined by Chi-square tests. All linkage maps were constructed using CarthaGène 1.2-LKH for Linux (de Givry et al. 2005) specifying a $\mathrm{BC}_{1} \mathrm{~F}_{4}$ genetic model. First, genetic maps for the three populations were calculated independently. A maximum distance of 30 centimorgans (cM) and a minimum logarithm of odds (LOD) threshold of 3 were used to partition markers into linkage groups. The most likely positions of the markers along the linkage groups were determined using the commands nicemapl, mfmapl, flips, build, and annealing. Cosegregating markers were merged into single markers. Colinearity of the three maps was visualized using MapChart v2.2 (Voorrips 2002) via SSR markers and co-located AFLP markers. These improved data sets were subsequently used for a joint analysis of all populations with CarthaGène. The three data sets (populations) were merged using the command dsmergor. This produces consensus data sets sharing marker order, but separate parameter estimates with per-data-set distances (CarthaGène user manual). For calculating $\mathrm{cM}$ distances the Kosambi mapping function was used. Linkage groups were assigned to chromosomes according to SSR markers and their map information from GrainGenes (http://wheat.pw. usda.gov/ggpages/maps.shtml). Maps were compared to the high-density wheat consensus SSR genetic map (Somers et al. 2004) available in GrainGenes.

\section{QTL mapping}

Quantitative trait loci calculations were carried out with $\mathrm{R}$ version 2.12.2 (R Development Core Team 2011) based on QTL expectations calculated at $2 \mathrm{cM}$ intervals with QGene 4.3.8 (Joehanes and Nelson 2008) from marker data and map information.

Linear models were fitted to estimate QTL effects on the analyzed traits. For trait FHB severity (AUDPC) the mean temperature over 4 days after first inoculation was included as a covariable. QTL for FHB severity were fitted 
individually for each experiment using the model $T_{i}=\mu+$ $M_{i}+t+\varepsilon_{i}$, where $\mu=$ general mean, $M_{i}=$ expected genotype of $i$ th QTL, $t=$ effect of temperature at flowering, $\varepsilon_{i}=$ random error. A multienvironment analysis was performed including all experiments, using the model $T_{i j k}=\mu+M_{i}+Y_{j}+I_{k}+t_{j k}+\varepsilon_{i j k}$, where $Y_{j}=$ effect of $j$ th year, $I_{k}=$ effect of $k$ th isolate, $t_{j k}=$ effect of temperature at flowering in the $j$ th year with the $k$ th isolate. QTL of morphological traits were calculated using the simplified model $T_{i}=\mu+M_{i}+\varepsilon_{i}$ and, for developmental-trait flowering time, the model $T_{i j}=\mu+M_{i}+Y_{j}+\varepsilon_{i j} . F$ statistics were converted into LOD values and the associated explained phenotypic variances were calculated. Additive effects were estimated as the regression coefficients for the corresponding $M_{i}$ terms.

For all analyses, LOD significance thresholds for type I error rates of $\alpha<0.1, \alpha<0.05$ and $\alpha<0.01$ were determined via 1,000 permutations. Linkage groups and LOD bars were drawn with MapChart v2.2.

\section{Results}

\section{Trait variation}

Mean values of the parents, means and ranges of the populations, least significant differences and broad-sense heritability for FHB severity (AUDPC) and for several morphological and developmental traits are summarized in Table 1. All populations displayed continuous distributions of AUDPC. None of the lines exhibited higher resistance than the resistant parent, but several lines from each population showed $(p<0.05)$ higher FHB severity than the susceptible parent (Fig. 1). The average FHB severity of the three populations was lowest in HTd, followed by FTd, and was highest in DTd. Generally experiments inoculated with $F$. culmorum had two- to threefold higher disease severity than those inoculated with $F$. graminearum. Correlation coefficients $(r)$ for AUDPC between averaged values of Fg and Fc experiments were high with $r=0.66$ for DTd and $r=0.77$ for FTd and HTd. Correlations between individual experiments were all positive and highly significant $(p<0.001)$ and showed ranges $r=0.44-0.53,0.37-0.63$, and $0.50-0.65$ for the DTd, FTd, and HTd populations, respectively.

Averaged across all experiments, the respective T. durum parents DS, Floradur and Helidur were 45, 46, and $44 \mathrm{~cm}$ shorter and flowered 9, 10, and 12 days earlier than the donor parent Td161. Compared to the highly FHB-resistant $T$. aestivum line CM-82036, which was included in all experiments as resistant check, Td161 was flowering 2 weeks later, was $35 \mathrm{~cm}$ taller, and had an average FHB severity at 26 days after inoculation of $12 \%$ while CM-82036 had $5 \%$. All populations showed significant variation for the developmental trait flowering time and for the morphological traits plant height, spike compactness and awn length (Table 1). A bimodal frequency distribution for plant height was apparent in populations DTd and HTd (Fig. 1). All populations showed highly significant correlations between FHB severity and plant height (Table 2), which was highest $(r=-0.70)$ in HTd. FHB severity, averaged across all experiments, was negatively correlated with flowering time in all populations (Table 2), but flowering time had no association with FHB severity in several individual experiments (Fg08 in population DTd, Fc06 in FTd, Fc06 and Fg08 in HTd). A positive correlation between spike compactness and FHB severity was evident in FTd and HTd. Taller plants as well as earlier-flowering lines were less infected and lines with compact spikes tended to be more infected. Awn length had a weak negative correlation with FHB severity in population HTd, with longer awns slightly decreasing FHB severity.

ANOVA for FHB severity (as AUDPC) yielded highly significant effects for all sources of variance (Table 3). Broad-sense heritabilities for means over all experiments were constant among the populations with $H^{2}=0.76-0.77$ (Table 1). Higher mean temperature during 4 days after first inoculation increased infection $(p<0.001)$ for experiments $\mathrm{Fg} 06$, Fc08, and $\mathrm{Fg} 08$ in all populations. To account for this dependence, temperature was incorporated as a co-variable in the QTL analysis model.

\section{Linkage maps}

Of the 237 SSR markers tested on the parents $191(80.6 \%)$ were polymorphic. The SSR and AFLP markers yielded 480, 311 and 295 polymorphic loci in populations DTd, FTd, and HTd. After cosegregating markers were merged into single markers, the final maps comprised 368, 248, and 239 loci, respectively, among which 102 markers mapped across all populations.

The observed allele segregation of the various markers fitted in most cases the expected ratio of a $\mathrm{BC}_{1} \mathrm{~F}_{4} \mathrm{RIL}$ population. Segregation distortion at $p<0.05$ was observed for 19 markers in DTd, 26 markers in FTd, and 19 markers in HTd.

The markers of population DTd fell into 38 linkage groups, of which $13(827 \mathrm{cM})$ could be assigned to genome A and $13(858 \mathrm{cM})$ to genome B, while $12(236 \mathrm{cM})$ could not be unambiguously assigned to a chromosome. Markers of population FTd fell into 36 linkage groups, consisting of $15(606 \mathrm{cM})$ on genome A, $12(686 \mathrm{cM})$ on genome B, and 9 (122 cM) unassigned groups, and for population HTd 32 groups consisted of $14(621 \mathrm{cM})$ on genome $\mathrm{A}, 10$ (755 $\mathrm{cM}$ ) on genome $\mathrm{B}$, and 8 unassigned $(139 \mathrm{cM})$. Total 
Table 1 Means of parents, mean, minimum and maximum values of populations, least significant differences at $\alpha<0.05$ (LSD) and broadsense heritability $\left(\mathrm{H}^{2}\right)$ or repeatability of analyzed traits

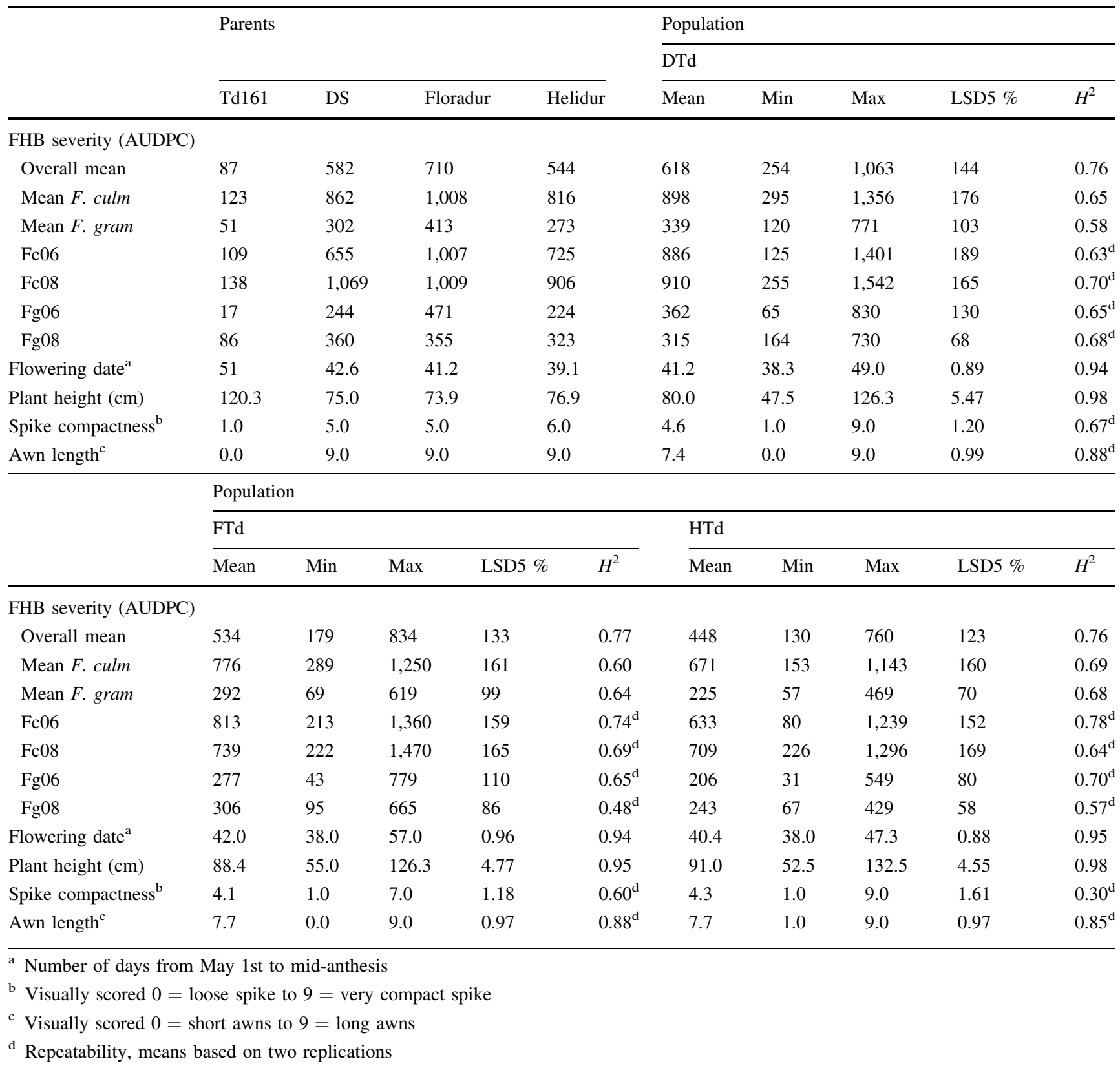

map lengths were $1,921,1,414$, and $1,515 \mathrm{cM}$ for DTd, FTd, and HTd, resulting in average marker distances of 5.2, 5.7 and $6.3 \mathrm{cM}$. For all chromosomes at least partial maps were obtained.

Haplotype comparison for SSR markers at Fhb1 (3BS) and Fhb2 (6BS)

An allele survey of Sumai-3, W14, CM-82036, and the parents Td161, DS, Floradur and Helidur with selected markers in the vicinity of $F h b 1$ and $F h b 2$ showed for all markers different alleles between the hexaploid and tetraploid lines studied. In the region surrounding Fhbl all hexaploid wheats shared one common haplotype, the durum parents Floradur and Helidur formed a second haplotype, alleles of DS differed at two markers (barc133, barc147) from Floradur and Helidur, and Td161 varied at all marker loci from all analyzed lines, except for umn10. All analyzed tetraploid wheat lines/ cultivars possessed a null allele at umn10. In the Fhb2 

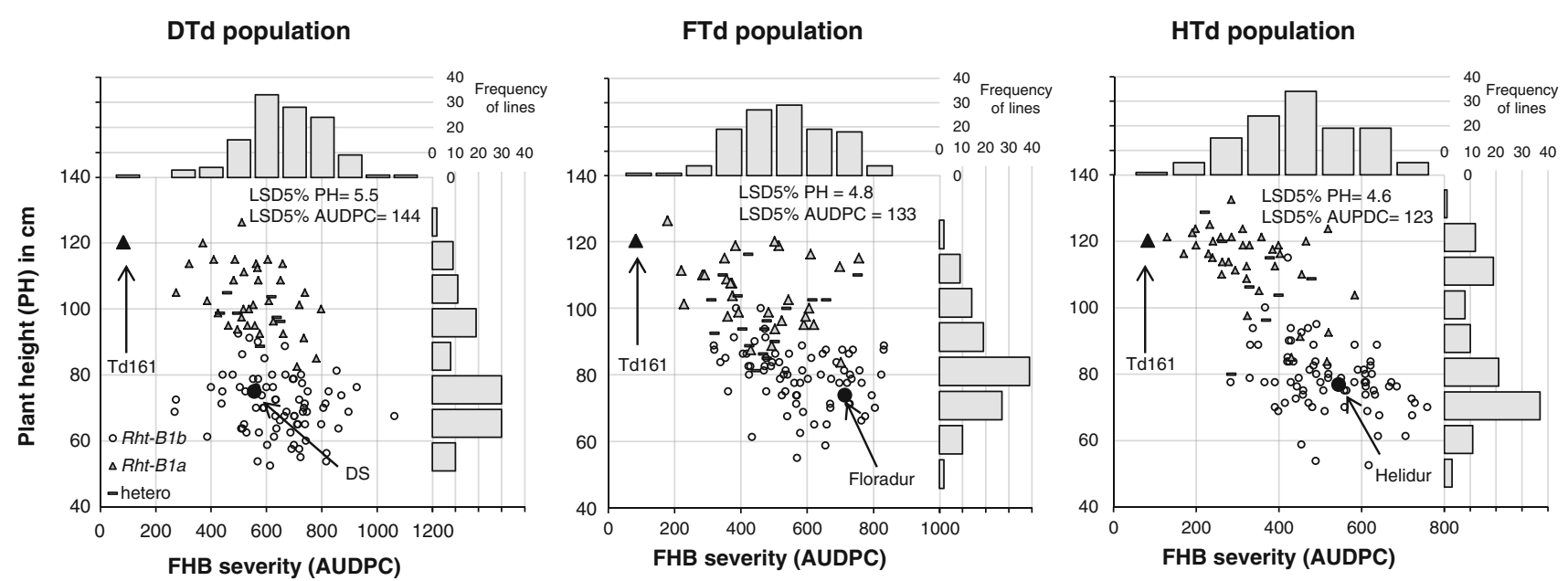

Fig. 1 Scatterplots of overall means for FHB AUDPC against plant height with marginal histograms of their frequency distribution. Allele status of $R h t-B 1$ of individual lines is represented by different symbols. Arrows indicate position of parents

Table 2 Pearson correlation coefficients between line mean values of FHB severity (AUDPC) and morphological traits

\begin{tabular}{lccc}
\hline & \multicolumn{3}{l}{ FHB severity measured in AUDPC } \\
\cline { 2 - 4 } & DTd & FTd & HTd \\
\hline Flowering date & $-0.28^{* *}$ & $-0.34 * * *$ & $-0.17^{*}$ \\
Plant height & $-0.40^{* * *}$ & $-0.39 * * *$ & $-0.70^{* * *}$ \\
Spike compactness & 0.14 & $0.24 * *$ & $0.21^{*}$ \\
Awn length & 0.13 & 0.06 & $-0.18^{*}$ \\
\hline
\end{tabular}

$* p<0.05$

$* * p<0.01$

$* * * p<0.001$

region, the hexaploid wheat lines that carry the $F h b 2$ resistance QTL, displayed one haplotype and the durum parents a second haplotype, with only Floradur differing from Helidur and DS by allele size at one marker (wmc398). Also at Fhb2 Td161 carried unique alleles at all tested marker loci.
QTL analysis

\section{Quantitative trait loci analysis for FHB severity}

Quantitative trait loci for FHB severity and their positions and statistical parameters are summarized in Table 4. Only QTL with LOD values $>3$ in two or more experiments or exceeding in one or more populations the LOD significance threshold for the multienvironment analysis are presented. Among the three populations, five genomic regions, on chromosomes 3B, 4B, 6A, 6B and 7B, were associated with FHB severity (Table 4; Fig. 2, Electronic Supplementary Material Fig. S2). Three of these QTL were detected in two or three populations. Except for QTL on chromosome 3B, the allele that improved resistance was derived from the T. dicoccum donor parent Td161.

The QTL on chromosome 3B close to Xbarcl33 appeared only in population FTd and was significant in two of the four experiments. For this region, the susceptible T. durum parent Floradur contributed the resistant allele. The FHB QTL on chromosome 4B was significant in all

Table 3 Analysis of variance for FHB severity measured in AUDPC across all experiments

\begin{tabular}{|c|c|c|c|c|c|c|c|c|c|}
\hline \multirow[t]{3}{*}{ Source } & \multicolumn{9}{|c|}{ Population } \\
\hline & \multicolumn{3}{|c|}{ DTd } & \multicolumn{3}{|l|}{ FTd } & \multicolumn{3}{|l|}{ HTd } \\
\hline & $d f$ & Mean square & $F$ value & $d f$ & Mean square & $F$ value & $d f$ & Mean square & $F$ value \\
\hline Blocks within Exp & 4 & $3,440,238$ & $127.4 *$ & 4 & $2,243.458$ & $97.8 *$ & 4 & 968,268 & $49.6^{*}$ \\
\hline Experiment & 3 & $26,997,987$ & $999.8^{*}$ & 3 & $20,080.798$ & $875.7 *$ & 3 & $16,925,090$ & $867.0^{*}$ \\
\hline Genotype & 134 & 183,847 & $6.8^{*}$ & 129 & 175.515 & $7.7 *$ & 126 & 160,476 & $8.2 *$ \\
\hline Genotype $\times$ Exp. & 401 & 43,462 & $1.6^{*}$ & 375 & 40.608 & $1.8^{*}$ & 376 & 37,837 & $1.9^{*}$ \\
\hline Error & 517 & 27,002 & & 494 & 14.214 & & 501 & 19,522 & \\
\hline
\end{tabular}

Significant at $* p<0.001$ 
Table 4 Summary of QTL for FHB severity (AUDPC) identified by simple interval mapping

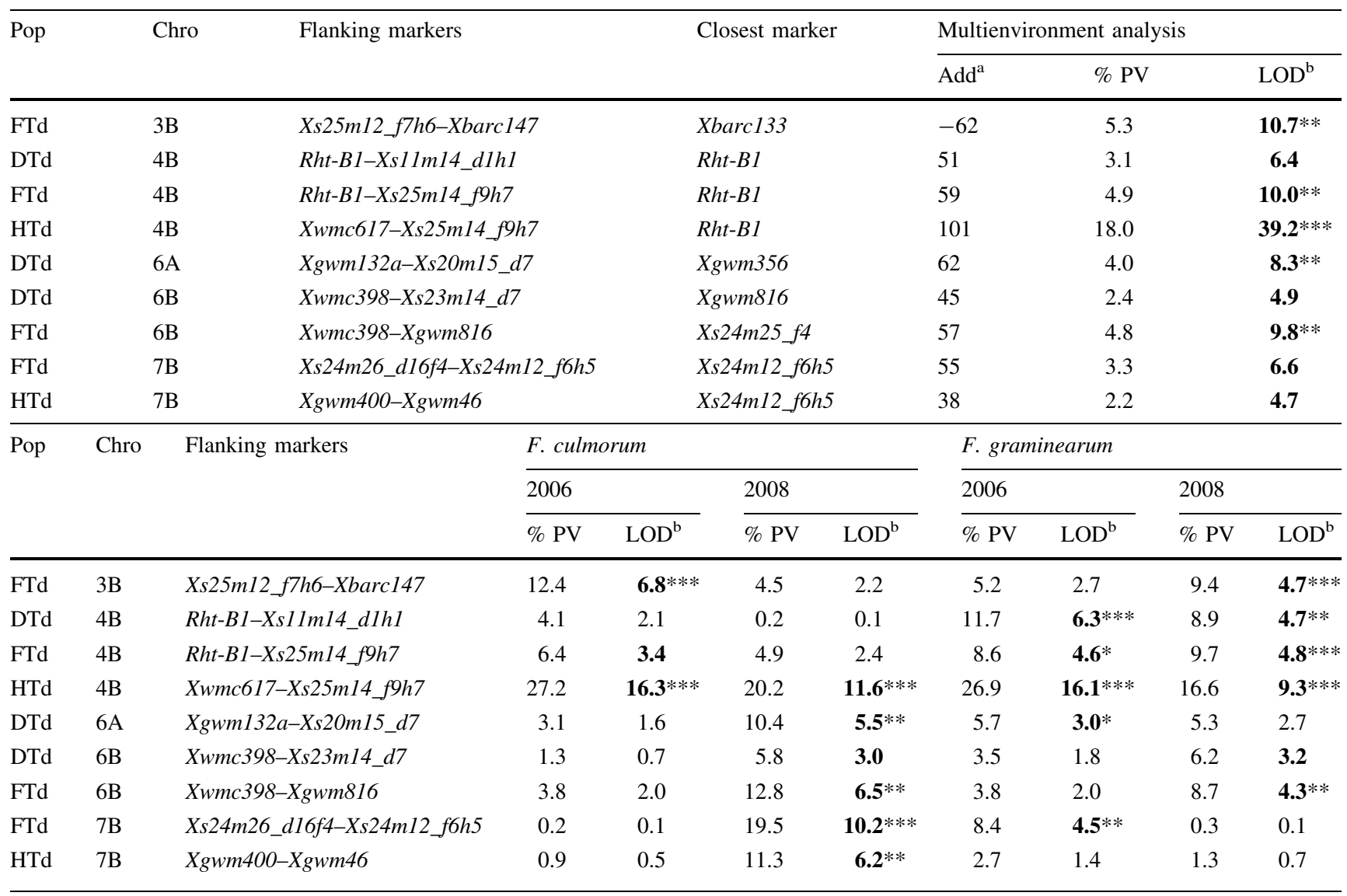

LOD values $\geq 3$ are printed in bold

$* \alpha 0.1<\mathrm{LOD} ; * * \alpha 0.05<\mathrm{LOD} ; * * * \alpha 0.01<\mathrm{LOD}$

${ }^{\text {a }}$ Positive additive effects denote that the T.diccocum allele reduces trait values relative to its respective T. durum allele

b Significance thresholds were estimated by permutation tests (number of iterations $=1,000$ ) for $\alpha 0.01, \alpha 0.05, \alpha 0.1$ for each experiment and for the multienvironment analysis of all populations

three populations and coincided with QTL for plant height at the Rht-Bl locus. This QTL for FHB was observed in $F$. graminearum-inoculated experiments of populations DTd and FTd and in all experiments of HTd. It had the greatest effect on FHB in population $\mathrm{HTd}$, where it explained $18 \%$ of the phenotypic variance (PV) in the multienvironment analysis. Populations DTd and FTd showed a QTL in the same region on chromosome 6B. This region spanned markers Xgwm816 and Xwmc397 and showed LOD values $>3$ in two experiments with both populations, but only the QTL in FTd was significant in individual experiments and in the multienvironment analysis. In addition, a QTL on chromosome 6A appeared in two experiments of population DTd. Finally, a QTL on 7B was significant in individual experiments of population FTd and HTd but not in the multienvironment analysis. This QTL showed peaks in both populations at $X s 24 m 12 \_f 6 h 5$ close to SSR marker Xgwm400 and overlapped with a QTL for flowering time.

\section{QTL analysis for developmental and morphological traits}

Quantitative trait loci and estimates of QTL effects of plant height, spike compactness, length of awns and flowering date are shown in Table 5. Linkage groups and position of QTL are depicted in Electronic Supplementary Fig. S2.

Population DTd and HTd showed one, and population FTd two QTL associated with plant height. The Rht-B1 QTL on 4B was significant in all populations. This QTL explained $56 \%$ of PV in population FTd and $68 \%$ in populations DTd and HTd. Lines homozygous for Rht-B1b allele were on average 25,32 , and $35 \mathrm{~cm}$ shorter compared to lines homozygous for the Rht-Bla wild-type allele in the respective populations FTd, DTd and HTd. Plant height in population FTd was influenced by a second QTL on 3A, which contributed $15 \%$ to the PV and accounted for on average a $13 \mathrm{~cm}$ height difference between homozygous lines of contrasting allele status. The Td161 allele on 4B and $3 \mathrm{~A}$ increased height. 


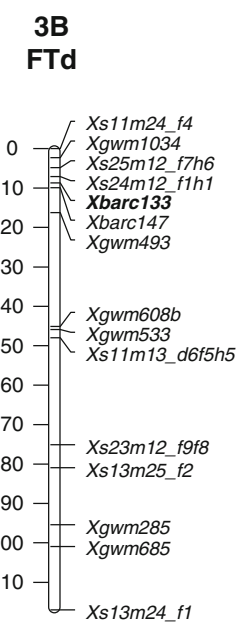

\section{B}

DTd

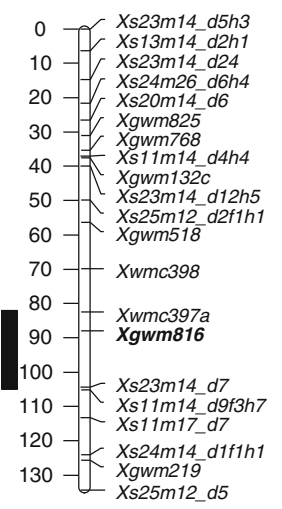

4B

DTd

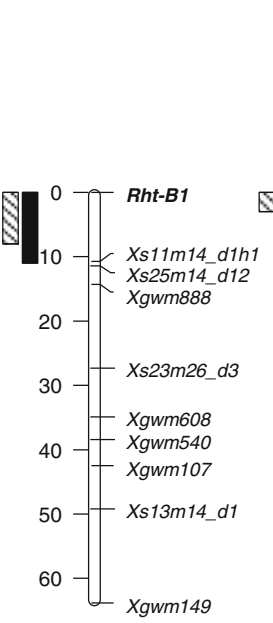

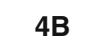

FTd

\section{$4 B$}

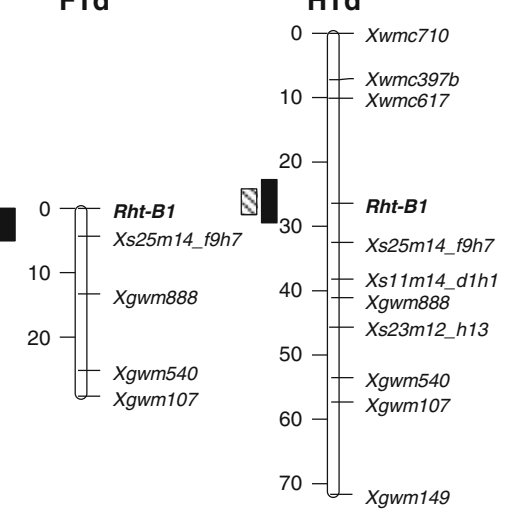

6A

DTd

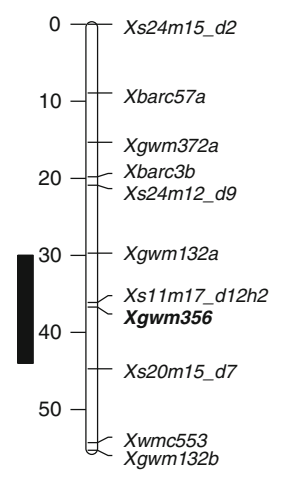

6B

FTd
7B

FTd
7B

HTd
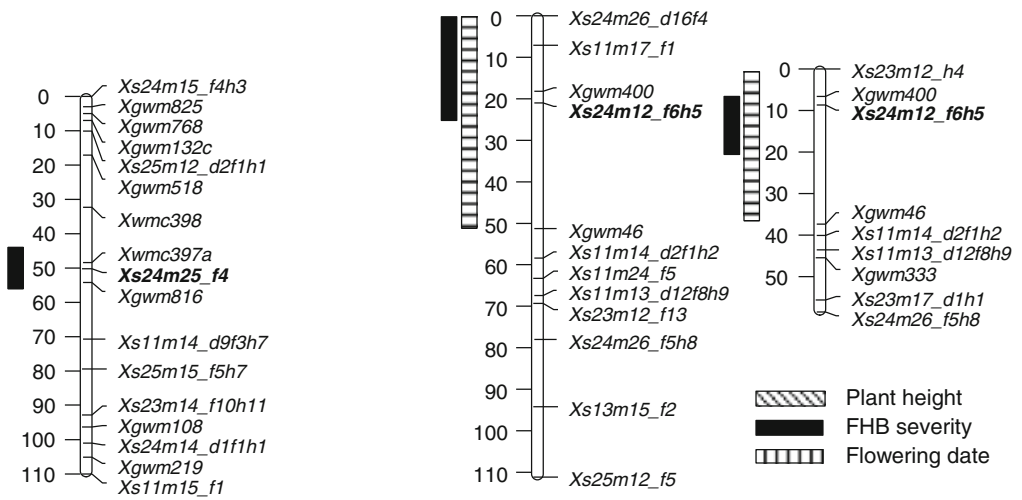

Fig. 2 Linkage maps and positions of QTL for FHB severity and QTL of coinciding morphological/developmental traits of the three populations. Loci closest to the QTL peak of FHB severity are in bold. QTL bars span a LOD drop of 1.5 from maximum LOD

Altogether four different genomic regions identified on chromosomes 2B, 4A, 5A, and on 7B affected the date of flowering. The strongest effect was from the QTL on 7B, which accounted for 11, 19, and $13 \%$ of PV for DTd, FTd, and HTd, respectively. This QTL coincided with a minor QTL for FHB severity. The Td161 allele retarded flowering except at QTL on 5A.

Spike compactness was influenced by two QTL, assigned to chromosome 5A and 7A. Both QTL were identified in two populations, with the T. durum allele associated with compactness on $5 \mathrm{~A}$ and laxness on 7A.

Three QTL on chromosomes 3B, 4A and 7A were associated with awn length. QTL on 4A and 7A were significant in all individual populations. The strongest effect was from the QTL on 4A which explained 30, 33, and $45 \% \mathrm{PV}$ in populations DTd, FTd and HTd, and a QTL on 7A contributed 16, 16, and $12 \%$ to PV, respectively. At all these QTL the Td161 allele conferred reduced awn length.

\section{Discussion}

By analyzing three back-cross populations between the FHB-resistant $T$. dicoccum donor line and three adapted T. durum varieties we combined QTL detection with QTL validation. The populations showed large genetic variation for FHB severity in the inoculated trials. The populations also segregated for plant morphological and developmental traits, such as plant height, awn length, spike morphology and flowering date.

Despite individual spray inoculation of each line followed by uniform mist irrigation, we found a negative correlation between FHB severity and plant height, as well as FHB severity and flowering date and a positive correlation between FHB severity and temperature at inoculation date. These results agree with previous reports. Particularly plant height has repeatedly been found associated with FHB severity measured in spray-inoculated experiments (e.g., Buerstmayr et al. 2000; Draeger et al. 


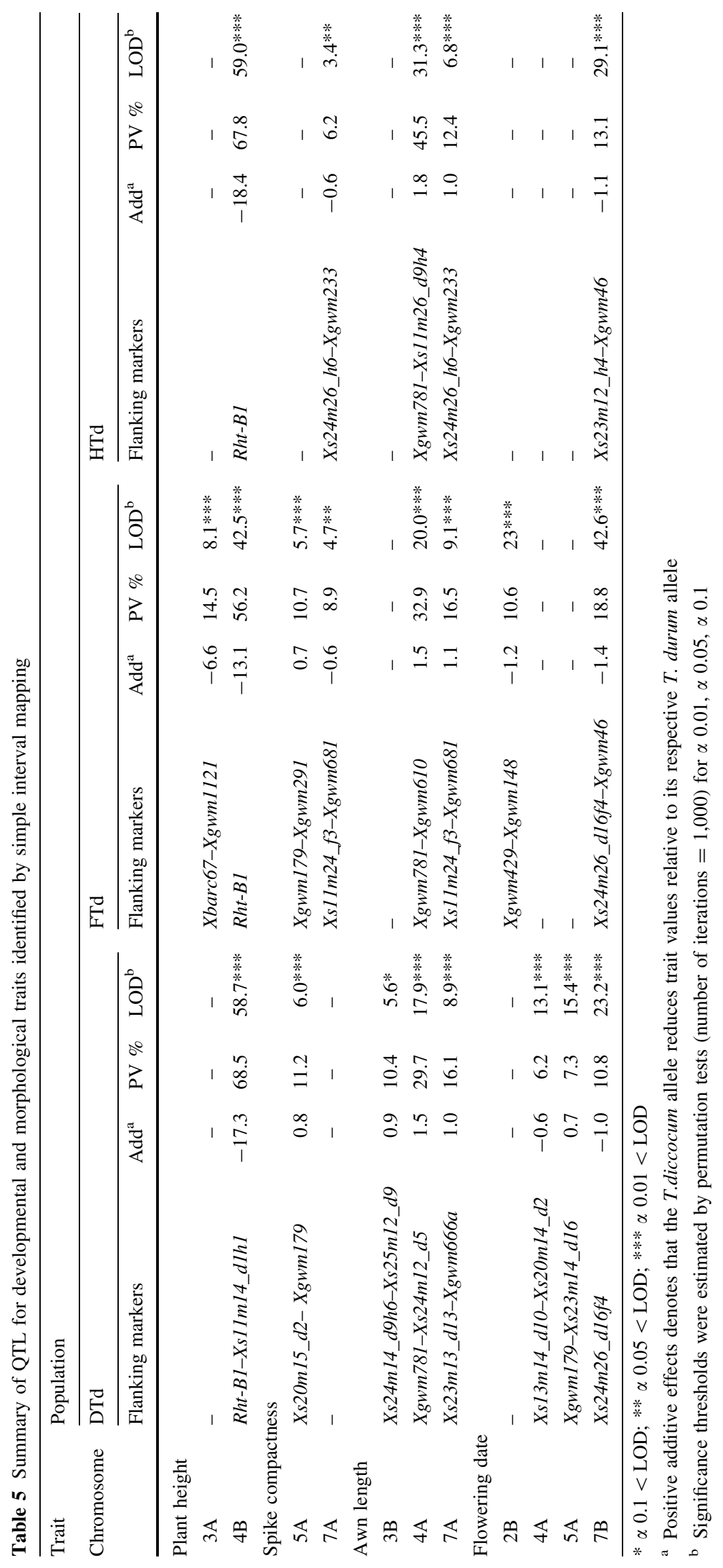


2007; Holzapfel et al. 2008; Srinivasachary et al. 2009; Steiner et al. 2004). Variation in plant height in our populations was large. In view of differences in plant height between the tallest and shortest lines of up to $80 \mathrm{~cm}$ it is likely that heads of taller plants dried off faster, and were therefore under lower infection pressure than short plants even in the presence of mist irrigation intended to standardize humidity. Thus, at least part of the negative correlation between height and FHB severity could be due to plant height per se.

\section{QTL for Fusarium head blight resistance}

Five QTL were found associated with FHB resistance, with T. dicoccum contributing the resistance-improving allele at four of these. FHB resistance in our populations is obviously under polygenic and complex genetic control. Three of four $T$. dicoccum-derived resistance QTL appeared in at least two populations, with only the minor QTL at chromosome 6A unique to one population. Interestingly, all detected QTL, except that on chromosome 6A, mapped to genomic regions previously associated with FHB resistance in hexaploid wheat.

3B: the $T$. durum cultivar Floradur contributed a resistance conferring QTL allele on chromosome 3BS close to Xbarc133. This QTL maps exactly to the position of the well-documented Fhbl (syn. Qfhs.ndsu-3BS) QTL from the cultivar Sumai-3 and other Asian resistance sources (Anderson et al. 2001; Liu et al. 2006, 2008; Waldron et al. 1999). To date, Fhbl has been found in more than 20 QTL mapping studies, all based on hexaploid Chinese resistance sources (Buerstmayr et al. 2009); this is the first report, where a resistance QTL at Fhbl was found in tetraploid wheat. Comparison of the allele size of SSR markers of the Fhb1-carrying hexaploid wheat cultivar Sumai-3 to alleles of the tetraploid wheat parents used in the present study with markers in close proximity to Fhbl suggests that the Fhb1 allele of Sumai-3 is not identical to the allele in Floradur. Interestingly, although the SSR marker haplotype around Fhbl of Floradur was identical to that of Helidur, the 3B QTL was not detected in the Helidur population.

4B: by far the largest contribution to FHB severity was due to the QTL on $4 \mathrm{~B}$, which coincided with the Rht-B1 locus. The FHB QTL at $R h t-B 1$ appeared in all populations, but its effect on FHB severity varied between populations. Since all populations were tested in the same environments, these differences can be attributed to their different genetic backgrounds or to sampling effects due to the relatively small population sizes. Notably, in F. graminearum-inoculated experiments with markedly lower average infection levels than in $F$. culmorum experiments the 4B QTL was always significant. In contrast, in the $F$. culmorum-inoculated experiments with high average FHB severity this QTL was significant only in population HTd. As resistance to FHB is non-species specific (Van Eeuwijk et al. 1995), this result suggests that above a certain infection pressure, the disease-reducing effect of increased height diminishes depending on the genetic background. In several independent studies in hexaploid wheat, the semi-dwarfing allele $R h t-D l b$ was strongly associated with increased FHB severity (Draeger et al. 2007; Hilton et al. 1999; Holzapfel et al. 2008; Srinivasachary et al. 2008; Voss et al. 2008), but the association of the homeologous gene Rht-Bl with FHB is less clear. Rht-Bl and Rht-Dl are orthologs of the Arabidopsis Gibberellin-insensitive (GAI) gene (Peng et al. 1999). Both genes exert, besides a strong effect on plant height, pleiotropic effects on various agronomic and quality traits (Elias and Manthey 2005). Miedaner and Voss (2008) compared Mercia-derived NILs (near-isogenic lines) carrying different $R h t$ alleles. They found an increased FHB rating in the presence of the $R h t-B 1 b$ allele, but the difference to Rht-Bla wild type was not significant. In a Soissons $\times$ Orvantis doubled-haploid population segregating for Rht-Dl and Rht-Bl only the Rht-Dl locus was associated with FHB resistance, whereas in a study with Mercia and Maris Huntsman-derived NILs, both $R h t-B 1 b$ and $R h t$ $D 1 b$ decreased type 1 resistance while $R h t-B 1 b$ increased type 2 resistance (Srinivasachary et al. 2008). Yan et al. (2011) reported increased FHB severity on short near-isogenic lines carrying different $R h t$ alleles. Interestingly, the negative effect of most semi-dwarf alleles, including Rht$B 1 b$, on type 1 resistance largely disappeared when the short isolines were physically elevated so that their spikes were positioned at the same height as those of their respective tall counterparts. This result indicated that the effect of stemshortening alleles on increasing FHB susceptibility is due mainly to plant height per se. In view of this and the other prior findings, we speculate that the FHB-resistanceimproving effect of the 4B QTL associated with the tall allele $R h t-B l a$ in our study is due partly to plant height per se. This speculation warrants further investigation.

6B: the position of the 6B FHB QTL shared by the DTd and FTd populations matches that of the well-documented Fhb2 QTL on 6BS. Resistance sources of Fhb2 in hexaploid wheat are Sumai-3 and related lines (Buerstmayr et al. 2009; Cuthbert et al. 2006; Häberle et al. 2009; Löffler et al. 2009; Shen et al. 2003). Besides in hexaploid wheat, a QTL corresponding to $F h b 2$ was reported in tetraploid wheat as well. Somers et al. (2006) mapped an FHB resistance QTL on 6BS in a doubled-haploid population of $T$. durum variety Strongfield $\times T$. carthlicum variety Blackbird, which was clearly coincident with Fhb2. Improved resistance was contributed either by $T$. carthlicum in the Strongfield $\times$ Blackbird population, or as in the present study by $T$. dicoccum. The SSR allele survey at Fhb2 revealed different haplotypes for the hexaploid 
resistance source Sumai-3 and the tetraploid resistant line T. dicoccum. The coincidence of QTL on chromosome 3B with $F h b 1$ and on $6 \mathrm{~B}$ with $F h b 2$ suggests that genetic variation of FHB resistance at the $F h b 1$ and $F h b 2$ loci is not restricted to hexaploid wheat, but that resistanceimproving alleles at these loci exist in some tetraploid wheat accessions as well.

7B: only a small impact on FHB resistance was attributed to chromosome 7BS, though it was significant in three experiments. This QTL overlapped with a QTL for flowering date. Several QTL mapping projects with hexaploid wheat populations identified association between FHB resistance factors and markers on chromosome 7BS. Schmolke et al. (2005) found in the Dream/Lynx population an overlap of FHB and heading date on this region of 7BS. Furthermore, minor QTL associated with FHB for this region were found in two independent studies with bread wheat (Jiang et al. 2007; Klahr et al. 2007), but no coinciding QTL for heading date were reported.

6A: an FHB resistance QTL on chromosome 6A near Xgwm356 is reported here for the first time. This QTL was, however, detected in only one population (DTd) and accordingly is less attractive for resistance breeding.

Although the broad-sense heritability coefficients for FHB severity measured by AUDPC in the investigated populations were high, the percentage of phenotypic variance explained by QTL was only moderate to low and varied widely between the populations. Although the failure to find effective resistance in extensive screens of T. durum accessions for FHB reaction (Elias et al. 2005) suggested a general lack of resistance genes in the durum wheat gene pool, the resistance-improving allele on 3B was derived from the T. durum parent. Likewise Somers et al. (2006), Gladysz et al. (2007) and Ghavami et al. (2011) found QTL at which FHB resistance was contributed by the T. durum parent. This means that durum wheat does not necessarily lack resistance alleles. These findings, together with the observation that resistance QTL introgressed from hexaploid wheat into durum wheat improved resistance in only a few cases (own unpublished data), support the hypothesis that either most durum wheats possess suppressors that silence or reduce the effect of resistanceimproving QTL (Stack et al. 2002, Garvin et al. 2009) or the D genome contributes resistance-inducing genes that are absent in durum wheat (Fakhfakh et al. 2011).

QTL for morphological and developmental traits and their association with FHB resistance

\section{QTL for flowering date}

Altogether four different QTL were associated with flowering date. A QTL on 7B with strong effects on flowering date was found in all three populations. This flowering-date QTL overlapped with a QTL for FHB resistance, with later flowering associated with reduced FHB severity. Flood and Halloran (1983) reported the presence of an Eps (earliness per se) gene on chromosome 7B, Kuchel et al. (2006) mapped a photoperiod QTL, Lin et al. (2008) reported a major early flowering QTL, and Sourdille et al. (2000) detected two minor QTL with overlapping confidence intervals in this region related to earliness per se or photoperiod response. Several studies have found positive associations between early flowering and FHB severity (e.g., Buerstmayr et al. 2011; Gervais et al. 2003; Holzapfel et al. 2008; Paillard et al. 2004; Schmolke et al. 2005; Steiner et al. 2004). No systematic association between flowering date and FHB severity was found in a multi-environment evaluation of 56 lines derived from several European winter wheat mapping populations tested in five different countries over 2 years. Presumably, environment-specific factors, most likely the weather conditions around flowering and inoculation time, caused either positive, negative or no correlations (Buerstmayr et al. 2008). This is in agreement with our result, where there was a negative correlation between flowering time and FHB severity for means over all experiments, but this dependence was not consistent across all individual experiments. Out of four QTL for flowering date, only the QTL on 7B coincided with FHB severity. As mentioned above FHB resistance QTL on 7BS were found in different mapping projects. Thus, it appears likely, that the 7BS FHB resistance QTL effect does not rely on a pleiotropic effect of flowering date only.

\section{QTL for plant height}

Our results confirmed the large effect of the $R h t-B l b$ allele on plant height, which segregated in all three populations. Only population FTd segregated for an additional plant height QTL on chromosome 3A. While Rht-Bl was also associated with FHB severity, as discussed above, the 3A plant height QTL was not. Our finding is thus in agreement with the literature. Numerous studies observed a co-location of plant height QTL with FHB resistance QTL (Buerstmayr et al. 2011; Draeger et al. 2007; Gervais et al. 2003; Häberle et al. 2009; Paillard et al. 2004; Schmolke et al. 2005; Voss et al. 2008), as discussed above, but not all plant height QTL influenced FHB severity.

\section{QTL for spike compactness}

Two minor QTL associated with spike compactness were found. Although this trait was moderately correlated with FHB severity, none of the detected compactness QTL overlapped with QTL for FHB resistance. 


\section{QTL for awn length}

Triticum dicoccum-161 had shorter awns than the T. durum parents. Awn length segregated in the populations and three QTL controlling this trait were found, with QTL on $4 \mathrm{~A}$ and 7A being detected across all populations, but none of these was associated with FHB resistance QTL. The 4A QTL may correspond to the $H d$ (hooded) gene on $4 \mathrm{~A}$ (Sears 1954; Rao 1981; Sourdille et al. 2002), while the awn length QTL at 7A is described here for the first time.

\section{Summary and conclusions}

Triticum dicoccum line 161 has been confirmed as highly FHB resistant. Though the $T$. dicoccum $\times T$. durumderived mapping populations segregated for FHB resistance, only a few QTL were discovered, all of relatively small effect, mapping to chromosomes 3B, 4B, 6A, 6B and 7B. All but the 6A QTL mapped to genomic regions where FHB resistance QTL were previously found in hexaploid wheat, indicating that some FHB-resistance genes are common to tetraploid and hexaploid wheat. The resistance QTL of the largest effect mapped to chromosome 4B at the position of the Rht-Bl plant height gene where the $T$. dicoccum allele enhanced FHB resistance and plant height. Selected moderately FHB-resistant experimental lines from this project are being used for further crossing and pyramiding FHB resistance into adapted durum wheat germplasm.

Acknowledgments We gratefully acknowledge financial support from the Austrian Science Fund (FWF), projects P17310-B05 and F37-11. We also thank Peter Jack and James Christopher (RAGT, Cambridge, UK) for their assistance in SSR marker genotyping. We acknowledge Dr. Jeannie Gilbert (Agriculture and Agri-Food Canada, Winnipeg) for supplying the T. dicoccum line 161. We thank Clay Sneller (Ohio State University, USA) for his suggestions on improving this manuscript.

Open Access This article is distributed under the terms of the Creative Commons Attribution License which permits any use, distribution, and reproduction in any medium, provided the original author(s) and the source are credited.

\section{References}

Andersen AL (1948) The development of Gibberella zeae head blight of wheat. Phytopathology 38:595-611

Anderson J, Stack R, Liu S, Waldron B, Fjeld A, Coyne C, MorenoSevilla B, Fetch J, Song Q, Cregan P, Frohberg R (2001) DNA markers for Fusarium head blight resistance QTLs in two wheat populations. Theor Appl Genet 102:1164-1168
Atanasoff D (1920) Fusarium-blight (scab) of wheat and other cereals. J Agric Res 20:1-32

Ban T, Watanabe N (2001) The effects of chromosomes 3A and 3B on resistance to Fusarium head blight in tetraploid wheat. Hereditas 135:95-99

Buerstmayr H, Steiner B, Lemmens M, Ruckenbauer P (2000) Resistance to Fusarium head blight in winter wheat: heritability and trait associations. Crop Sci 40:1012-1018

Buerstmayr H, Lemmens M, Hartl L, Doldi L, Steiner B, Stierschneider M, Ruckenbauer P (2002) Molecular mapping of QTLs for Fusarium head blight resistance in spring wheat. I. Resistance to fungal spread (type II resistance). Theor Appl Genet 104:84-91

Buerstmayr H, Stierschneider M, Steiner B, Lemmens M, Griesser M, Nevo E, Fahima T (2003) Variation for resistance to head blight caused by Fusarium graminearum in wild emmer (Triticum dicoccoides) originating from Israel. Euphytica 130:17-23

Buerstmayr H, Lemmens M, Schmolke M, Zimmermann G, Hartl L, Mascher F, Trottet M, Gosman NE, Nicholson P (2008) Multienvironment evaluation of level and stability of FHB resistance among parental lines and selected offspring derived from several European winter wheat mapping populations. Plant Breed 127:325332

Buerstmayr H, Ban T, Anderson JA (2009) QTL mapping and marker-assisted selection for Fusarium head blight resistance in wheat: a review. Plant Breed 128:1-26

Buerstmayr M, Lemmens M, Steiner B, Buerstmayr H (2011) Advanced backcross QTL mapping of resistance to Fusarium head blight and plant morphological traits in a Triticum macha $\times$ T. aestivum population. Theor Appl Genet 123:293-306

Chen XF, Faris JD, Hu JG, Stack RW, Adhikari T, Elias EM, Kianian SF, Cai XW (2007) Saturation and comparative mapping of a major Fusarium head blight resistance QTL in tetraploid wheat. Mol Breed 19:113-124

Clarke J, Thomas J, Fedak G, Somers D, Gilbert J, Pozniak C, Fernandez M, Comeau A (2004) Progress in improvement of Fusarium resistance of durum wheat. In: Canty SM, Boring T, Wardwell J, Ward RW (eds) Proc 2nd Int Symp on Fusarium Head Blight. Orlando, FL, 11-15 Dec 2004, Michigan State University, East Lansing, MI, p 43

Cook JR (1981) Fusarium diseases of wheat and other small grains in North America. In: Nelson PE, Toussoun TA, Cook RJ (eds) Fusarium: diseases, biology and taxonomy. Pennsylvania State University Press, University park, pp 39-52

Crute IR, de Wit PJGM, Wade M (1985) Mechanisms by which genetically controlled resistance and virulence influence host colonization by fungal and bacterial parasites. In: Fraser RSS (ed) Mechanism of resistance to plant diseases. Martinus Nijhoff/Dr. W. Junk Publishers, Dordrecht, pp 197-309

Cuthbert P, Somers D, Brule-Babel A (2006) Mapping of Fhb2 on chromosome 6BS: a gene controlling Fusarium head blight field resistance in bread wheat (Triticum aestivum L.). Theor Appl Genet 114:429-437

de Givry S, Bouchez M, Chabrier P, Milan D, Schiex T (2005) Carthagene: multipopulation integrated genetic and radiated hybrid mapping. Bioinformatics 21:1703-1704

Draeger R, Gosman N, Steed A, Chandler E, Thomsett M, Srinivasachary AN, Schondelmaier J, Buerstmayr H, Lemmens M, Schmolke M, Mesterhazy A, Nicholson P (2007) Identification of QTLs for resistance to Fusarium head blight, DON accumulation and associated traits in the winter wheat variety Arina. Theor Appl Genet 115:617-625

Elias EM, Manthey FA (2005) Durum wheat breeding at North Dakota State University. In: Royo C, Nachit MM, Di Fonzo N, Araus JL, Pfeiffer WH, Slafer GA (eds) Durum wheat breeding: current approaches and future strategies. Food Products Press, New York, pp 939-962 
Elias EM, Manthey FA, Stack RW, Kianian SF (2005) Breeding efforts to develop Fusarium head blight resistant durum wheat in North Dakota. In: Canty SM, Boring T, Wardwell J, Siler L, Ward RW (eds) Proc 2005 National Fusarium Head Blight Forum. Milwaukee, WI, 11-13 Dec 2005, Michigan State University, East Lansing, pp 25-26

Ellis M, Spielmeyer W, Gale K, Rebetzke G, Richards R (2002) "Perfect" markers for the Rht-B1b and Rht-D1b dwarfing genes in wheat. Theor Appl Genet 105:1038-1042

Fakhfakh MM, Yahyaoui A, Rezgui S, Elias EM, Daaloul A (2011) Inheritances of Fusarium head blight resistance in a cross involving local and exotic durum wheat cultivars. Crop Sci $51: 2517-2524$

Flood RG, Halloran GM (1983) The influence of certain chromosomes of the hexaploid wheat cultivar Thatcher on time to ear emergence in Chinese Spring. Euphytica 32:121-124

Garvin D, Stack R, Hansen J (2009) Quantitative trait locus mapping of increased Fusarium head blight susceptibility associated with a wild emmer wheat chromosome. Phytopathology 99:447-452

Gervais L, Dedryver F, Morlais JY, Bodusseau V, Negre S, Bilous M, Groos C, Trottet M (2003) Mapping of quantitative trait loci for field resistance to Fusarium head blight in an European winter wheat. Theor Appl Genet 106:961-970

Ghavami F, Elias EM, Mamidi S, Ansari O, Sargolzaei M, Adhikari T, Mergoum M, Kianian SF (2011) Mixed model association mapping for Fusarium head blight resistance in Tunisian-derived durum wheat populations. G3 (Bethesda, Md) 1:209-218

Gilbert J, Tekauz A (2000) Review: recent developments in research on Fusarium head blight of wheat in Canada. Can J Plant Pathol 22:1-8

Gilbert J, Procunier JD, Aung T (2000) Influence of the D genome in conferring resistance to Fusarium head blight in spring wheat. Euphytica 114:181-186

Gill BS, Appels R, Botha-Oberholster AM, Buell CR, Bennetzen JL, Chalhoub B, Chumley F, Dvorak J, Iwanaga M, Keller B, Li W, McCombie WR, Ogihara Y, Quetier F, Sasaki T (2004) A workshop report on wheat genome sequencing: international Genome Research on Wheat Consortium. Genetics 168:10871096

Gladysz C, Lemmens M, Steiner B, Buerstmayr H (2007) Evaluation and genetic mapping of resistance to Fusarium head blight in Triticum dicoccoides. Isr J Plant Sci 55:263-266

Häberle J, Schweizer G, Schondelmaier J, Zimmermann G, Hartl L (2009) Mapping of QTL for resistance against Fusarium head blight in the winter wheat population Pelikan//Bussard/ Ning8026. Plant Breed 128:27-35

Hartl L, Mohler V, Zeller FJ, Hsam SLK, Schweizer G (1999) Identification of AFLP markers closely linked to the powdery mildew resistance genes Pmlc and Pm4a in common wheat (Triticum aestivum L.). Genome 42:322-329

Hilton A, Jenkinson P, Hollins T, Parry D (1999) Relationship between cultivar height and severity of Fusarium ear blight in wheat. Plant Pathol 48:202-208

Holzapfel J, Voss H, Miedaner T, Korzun V, Haberle J, Schweizer G, Mohler V, Zimmermann G, Hartl L (2008) Inheritance of resistance to Fusarium head blight in three European winter wheat populations. Theor Appl Genet 117:1119-1128

Huhn M, Elias E, Ghavami F, Kianian S, Chao S, Zhong S, Alamri M, Yahyaoui A, Mergoum M (2012) Tetraploid Tunisian wheat germplasm as a new source of Fusarium head blight resistance. Crop Sci 52:136-145

Jiang G, Shi J, Ward R (2007) QTL analysis of resistance to Fusarium head blight in the novel wheat germplasm CJ 9306. I. Resistance to fungal spread. Theor Appl Genet 116:3-13

Joehanes R, Nelson J (2008) QGene 4.0, an extensible Java QTLanalysis platform. Bioinformatics 24:2788-2789
Joppa LR, Williams ND (1988) Langdon durum substitution lines and aneuploid analysis in tetraploid wheat. Genome 30:222-228

Kishii M, Ban T, Ammar K (2005) Improvement of FHB resistance of durum wheat. In: Canty SM, Boring T, Wardwell J, Siler L, Ward RW (eds) Proc 2005 National Fusarium Head Blight Forum. Milwaukee, WI, 11-13 Dec 2005, Michigan State University, East Lansing, p 52

Klahr A, Zimmermann G, Wenzel G, Mohler V (2007) Effects of environment, disease progress, plant height and heading date on the detection of QTLs for resistance to Fusarium head blight in an European winter wheat cross. Euphytica 154:17-28

Kuchel H, Hollamby G, Langridge P, Williams K, Jefferies S (2006) Identification of genetic loci associated with ear-emergence in bread wheat. Theor Appl Genet 113:1103-1112

Kumar S, Stack R, Friesen T, Faris J (2007) Identification of a novel Fusarium head blight resistance quantitative trait locus on chromosome 7A in tetraploid wheat. Phytopathology 97:592597

Lin F, Xue S, Tian D, Li C, Cao Y, Zhang Z, Zhang C, Ma Z (2008) Mapping chromosomal regions affecting flowering time in a spring wheat RIL population. Euphytica 164:769-777

Liu S, Zhang X, Pumphrey MO, Stack RW, Gill BS, Anderson JA (2006) Complex microcolinearity among wheat, rice, and barley revealed by fine mapping of the genomic region harboring a major QTL for resistance to Fusarium head blight in wheat. Funct Integr Genomics 6:83-89

Liu S, Pumphrey M, Gill B, Trick H, Zhang J, Dolezel J, Chalhoub B, Anderson J (2008) Toward positional cloning of Fhbl, a major QTL for Fusarium head blight resistance in wheat. Cereal Res Commun 36:195-201

Löffler M, Schon CC, Miedaner T (2009) Revealing the genetic architecture of FHB resistance in hexaploid wheat (Triticum aestivum L.) by QTL meta-analysis. Mol Breed 23:473-488

McMullen MP, Jones R, Gallenberg D (1997) Scab of wheat and barley: a re-emerging disease of devastating impact. Plant Dis 81:1340-1348

Mesterhazy A (1995) Types and components of resistance to Fusarium head blight of wheat. Plant Breed 114:377-386

Miedaner T, Voss H (2008) Effect of dwarfing Rht genes on Fusarium head blight resistance in two sets of near-isogenic lines of wheat and check cultivars. Crop Sci 48:2115-2122

Miedaner T, Reinbrecht C, Lauber U, Schollenberger M, Geiger H (2001) Effects of genotype and genotype-enviromment interaction on deoxynivalenol accumulation and resistance to Fusarium head blight in rye, triticale, and wheat. Plant Breed 120:97-105

Miller JD, Stack RW, Joppa LR (1998) Evaluation of Triticum turgidum L. var. dicoccoides for resistance to Fusarium head blight and stem rust. In: Slinkard AE (ed) Proc 9th Int Wheat Gen Symp. Saskatoon, SK, 2-7 Aug 1998. Univ of Saskatchewan Ext Press, Saskatoon, pp 292-293

Nyquist WE (1991) Estimation of heritability and prediction of selection response in plant populations. Crit Rev Plant Sci 10:235-322

Oliver RE, Xu SS, Cai W, Stack RW (2004) Evaluation of tetraploid wheat germplasm for resistance to Fusarium head blight. In: Canty SM, Boring T, Wardwell J, Ward RW (eds) Proc 2nd Int Symp Fusarium Head Blight. Orlando, FL, 11-15 Dec 2004, Michigan State University Printing, East Lansing, pp 25-26

Oliver R, Stack R, Miller J, Cai X (2007) Reaction of wild emmer wheat accessions to Fusarium head blight. Crop Sci 47:893-899

Oliver RE, Cal X, Friesen TL, Halley S, Stack RW, Xu SS (2008) Evaluation of Fusarium head blight resistance in tetraploid wheat (Triticum turgidum L.). Crop Sci 48:213-222

Otto CD, Kianian SF, Elias EM, Stack RW, Joppa LR (2002) Genetic dissection of a major Fusarium head blight QTL in tetraploid wheat. Plant Mol Biol 48:625-632 
Paillard S, Schnurbusch T, Tiwari R, Messmer M, Winzeler M, Keller B, Schachermayr G (2004) QTL analysis of resistance to Fusarium head blight in Swiss winter wheat (Triticum aestivum L.). Theor Appl Genet 109:323-332

Parry DW, Jenkinson P, McLeod L (1995) Fusarium ear blight (scab) in small grain cereals-a review. Plant Pathol 44:207-238

Peng J, Richards D, Hartley N, Murphy G, Devos K, Flintham J, Beales J, Fish L, Worland A, Pelica F, Sudhakar D, Christou P, Snape J, Gale M, Harberd N (1999) 'Green revolution' genes encode mutant gibberellin response modulators. Nature 400: 256-261

Pestsova E, Ganal MW, Roder MS (2000) Isolation and mapping of microsatellite markers specific for the D genome of bread wheat. Genome 43:689-697

R Development Core Team (2011) R: a language and environment for statistical computing. R Foundation for statistical computing, Vienna

Rao MVP (1981) Telocentric mapping of the awn inhibitor gene $H d$ on chromosome 4B of common wheat. Cereal Res Commun 9:335-337

Roeder SM, Korzun K, Wendehake K, Plaschke J, Tixier HM, Leroy P, Ganal WM (1998) A microsatellite map of wheat. Genetics 149:2007-2023

Saghai Maroof MAK, Soliman RA, Jorgensen RA, Allard RW (1984) Ribosomal DNA spacer length polymorphism in barley: Mendelian inheritance, chromosomal location and population dynamics. Proc Natl Acad Sci USA 81:8014-8018

SAS Institute Inc (2008) SAS/STAT ${ }^{\circledR} 9.2$ user's guide. Cary, NC

Schmolke M, Zimmermann G, Buerstmayr H, Schweizer G, Miedaner T, Korzun V, Ebmeyer E, Hartl L (2005) Molecular mapping of Fusarium head blight resistance in the winter wheat population Dream/Lynx. Theor Appl Genet 111:747-756

Schroeder HW, Christensen JJ (1963) Factors affecting resistance of wheat to scab caused by Gibberella zeae. Phytopathology 53:831-838

Sears ER (1954) The aneuploids of common wheat. Univ Missouri Res Bull 572:1-58

Shen X, Zhou M, Lu W, Ohm H (2003) Detection of Fusarium head blight resistance QTL in a wheat population using bulked segregant analysis. Theor Appl Genet 106:1041-1047

Somers DJ, Isaac P, Edwards K (2004) A high-density microsatellite consensus map for bread wheat (Triticum aestivum L.). Theor Appl Genet 109:1105-1114

Somers DJ, Fedak G, Clarke J, Cao WG (2006) Mapping of FHB resistance QTLs in tetraploid wheat. Genome 49:1586-1593

Song QJ, Shi JR, Singh S, Fickus EW, Costa JM, Lewis J, Gill BS, Ward R, Cregan PB (2005) Development and mapping of microsatellite (SSR) markers in wheat. Theor Appl Genet 110:550-560
Sourdille P, Snape J, Cadalen T, Charmet G, Nakata N, Bernard S, Bernard M (2000) Detection of QTLs for heading time and photoperiod response in wheat using a doubled-haploid population. Genome 43:487-494

Sourdille P, Cadalen T, Gay G, Gill B, Bernard M (2002) Molecular and physical mapping of genes affecting awning in wheat. Plant Breed 121:320-324

Srinivasachary A, Gosman N, Steed A, Simmonds J, LeveringtonWaite M, Wang Y, Snape J, Nicholson P (2008) Susceptibility to Fusarium head blight is associated with the Rht-Dlb semidwarfing allele in wheat. Theor Appl Genet 116:1145-1153

Srinivasachary A, Gosman N, Steed A, Hollins T, Bayles R, Jennings P, Nicholson P (2009) Semi-dwarfing Rht-Bl and Rht-Dl loci of wheat differ significantly in their influence on resistance to Fusarium head blight. Theor Appl Genet 118:695-702

Stack RW, Faris J (2006) Identification of a Fusarium head blight resistance QTL on chromosome 6B in tetraploid wheat (abstract). Plant and Animal Genome XIV Conference. Abstract no P285:172

Stack RW, Elias EM, Fetch JM, Miller JD, Joppa LR (2002) Fusarium head blight reaction of Langdon durum-Triticum dicoccoides chromosome substitution lines. Crop Sci 42:637-642

Steiner B, Lemmens M, Griesser M, Scholz U, Schondelmaier J, Buerstmayr H (2004) Molecular mapping of resistance to Fusarium head blight in the spring wheat cultivar Frontana. Theor Appl Genet 109:215-224

Van Eeuwijk FA, Mesterhazy A, Kling CI, Ruckenbauer P, Saur L, Bürstmayr H, Lemmens M, Keizer LCP, Maurin N, Snijders CHA (1995) Assessing non-specificity of resistance in wheat to head blight caused by inoculation with European strains of Fusarium culmorum, $F$. graminearum and $F$. nivale using a multiplicative model for interaction. Theor Appl Genet 90:221228

Voorrips RE (2002) MapChart: software for the graphical presentation of linkage maps and QTLs. J Hered 93:77-78

Vos P, Hogers R, Bleeker M, Reijans M, van de Lee T, Horens M, Frijters A, Pot J, Peleman J, Kuiper M, Zabeau M (1995) AFLP: a new technique for DNA fingerprinting. Nucleic Acids Res 23:4407-4414

Voss H, Holzapfel J, Hartl L, Korzun V, Rabenstein F, Ebmeyer E, Coester H, Kempf H, Miedaner T (2008) Effect of the Rht-Dl dwarfing locus on Fusarium head blight rating in three segregating populations of winter wheat. Plant Breed 127:333-339

Waldron BL, Moreno-Sevilla B, Anderson JA, Stack RW, Frohberg RC (1999) RFLP mapping of QTL for Fusarium head blight resistance in wheat. Crop Sci 39:805-811

Yan W, Li H, Cai S, Ma H, Rebetzke G, Liu C (2011) Effects of plant height on type I and type II resistance to Fusarium head blight in wheat. Plant Pathol 60:506-512 